\title{
Cultivar development of allogamous crops
}
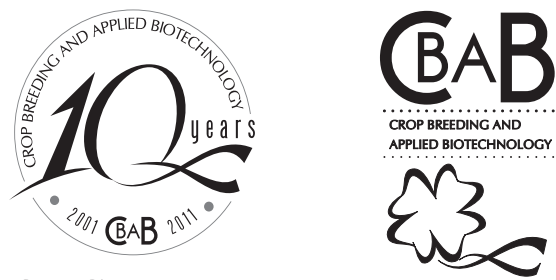

\author{
Cláudio Lopes de Souza Jr. ${ }^{1}$
}

Received 2 April 2011

Accepted 25 May 2011

\begin{abstract}
Objectives of this review were to present the state of the art of the technologies used to develop cultivars in allogamous species, excluding the perennial and asexually propagated species. It was reviewed the genetic structure of these species and its relationship with the development of cultivars, the technologies used to develop hybrids and improved open-pollinated varieties and their $F_{1}$ 's, and the impact of the biotechnology and the mixed models on the development of cultivars. A summary of results from the researches developed in the maize breeding project at the Department of Genetics of the Agriculture College "Luiz de Queiroz" will be presented.
\end{abstract}

Key words: cultivar, hybrids, molecular markers, recurrent selection, mixed models.

\section{INTRODUCTION}

The procedures used to develop cultivars are determined by the mode of reproduction of the crop species since different modes of reproduction lead to different genetic population structures. Allogamous species are those in which at least $95 \%$ of the natural form of reproduction occurs through crosses among plants, and then in each generation the genotypes are developed by the union of a female and male gamete from different plants at random in a population. Several mechanisms are present in these species to prevent the occurrence of self-fertilization as protandry, protogyny, monoecism, dioecism, and the diverse forms of self-incompatibility. Important crop species are included in this group as maize, sunflower, eucalyptus, sugar beet, cacao, onion, broccoli, cauliflower, Brussels sprouts, carrot, mango, avocado, and so on.

These species are sources of several products as ration for animals, oil, sugar, cellulose, fruits, vegetables, etc. Then, each species present specific problems that have to be considered in their breeding programs, as the increase of productivity and decrease of plant lodging in maize, increase of the quality and disease resistance in the vegetables, increase of cellulose content and decrease of lignin content in eucalyptus for paper production and enhancement of the wood properties for furniture production, etc. However, the genetic basis of plant breeding for these species are common; i.e., the same genetic technologies are used to develop cultivars in these crop species. Thus, the objective of this paper is to summarize the genetic principles underlying the development of cultivars in most of these species, excluding those perennial and/or asexually propagated species that due to the generation overlap some specific procedures should be employed.

\section{GENETIC STRUCTURE OF POPULATIONS}

Plants of a random-mating population have part of the loci in heterozygous and part in homozygous state and, in general, they have several alleles. Since the genotypes are formed at random in each generation, the

\footnotetext{
${ }^{1}$ Escola Superior de Agricultura "Luiz de Queiroz”, Departamento de Genética, C.P. 83, 13.400-970, Piracicaba, SP, Brazil.*E-mail: clsouza@esalq.usp.br
} 
plants did not transfer their genotypes to the next generation. Also, the populations maintain a high genetic load since the loci in heterozygous state allow that recessive lethal or deleterious alleles be maintained in the populations, and then, the populations in general present high inbreeding depression, and the cross of unrelated genotypes usually present high magnitudes of heterosis. Inbreeding depression and heterosis are expressed for several traits, but mainly for those ones in which the levels of dominance are high. As a consequence, allogamous species are very sensitive to the effects of the genetic drift, which has several consequences for both breeding and maintenance of germplasm banks.

\section{DEVELOPMENT OF CULTIVARS}

\section{Types of cultivars}

The most common types of cultivars from allogamous species are: hybrids from inbred or partially inbred lines and open-pollinated varieties. Hybrids are developed from crosses of inbred lines or partially inbred lines; highly inbred lines are used in those species that, despite the inbreeding depression, their levels of seed yield do not preclude their commercial use as maize and sunflower; on the other hand some species as carrots are quite sensitive to the inbreeding depression and only hybrids from partially inbred lines can be used. Open-pollinated populations (varieties) are used as cultivars in crop species that are so sensitive to inbreeding depression that do not allow the development of inbred lines, or in crop species in which the breeding programs are not well developed. However, hybrids should be the cultivar of choice since they are the best genotypes from a population or interpopulation hybrids.

\section{Development of base populations}

This phase is the most crucial in any breeding program, since the base populations will be the sources of the new cultivars; i.e., the genotypes that should outperform the current cultivars. Base populations are developed by crosses of selected genotypes; and the most common type of population is developed by cross of two genotypes, namely biparental crosses, although some programs also use populations developed by crosses involving three or more genotypes. General and specific criteria are used to develop the base populations to enhance the probability that the genotypes selected from them will outperform the current cultivars. The general criteria are those that are used for all breeding programs, regardless of the species, and the specific criteria are used to fulfill the needs of the farmers/consumers/processors in the plant breeding programs. So, only the general criteria will be presented, that could meet the needs of any breeding program, that is, to develop populations with adequate means and levels of genetic variability for the most important traits.

The general criteria are: i) use of elite genotypes (inbreds, hybrids) as parental for crossing or selfing; ii) information on the pedigree of these genotypes; iii) information on the genetic divergence of the parental genotypes; iv) performance of the parental genotypes in the target environments for which the cultivars are to be developed. The first criterion is to take advantage of the selection used to develop them, and thus, the elite genotypes will have high concentration of favorable alleles for different traits; the second criterion is to avoid crosses of related genotypes; the third criterion is to increase the probability of generate transgressive genotypes, and the fourth criterion is to develop populations for the environments in which the cultivars will be grown. It should be noticed that several base populations are developed to enhance the probability to develop cultivars, but usually selection is carried out among these populations in the initial phases of the breeding programs to concentrate efforts and resources in the most promising base populations (Souza Jr. 2001).

There is some debate on the number of population versus the number of genotypes that should be sampled from each population. However, as the use of large number of populations with few genotypes sampled from each one and the use of few number of populations with a large number of genotypes sampled have been used successfully, it seems more important the selection of the parental genotypes to develop the base populations. In this context it should be noticed that the improvement of the base populations by recurrent selection will allow the use of these populations for a long-term as source of cultivars.

\section{Hybrids from inbred lines}

Hybrids developed from crosses of inbred or partly inbred lines are the cultivars of choice for the species focused in this review, since they are the best genotypes of the populations or the interpopulations. Inbred lines are developed by six or seven generations of self-fertilization or by doubled-haploid (DH) procedure; and their crosses will give rise to the hybrids. As each inbred line produces only one type of gamete and its genotype could be 
maintained and multiplied, the genotypes of the crosses between the inbreds could also be maintained and multiplied for several generations. This is the genetic basis for developing hybrids from inbred lines.

There are several types of hybrids, as doublecrosses, three-way crosses, single-crosses, and modified single-crosses. A single-cross is produced from the cross of two inbred lines, the three-way cross from the cross of a single-cross and an inbred line, and the double-cross from the cross of two single-crosses. However, as the single-crosses should be the hybrid of choice, since its performance and uniformity are better than the other types of hybrids, only the development of the single-crosses will be described.

The base populations are allocated in different heterotic groups to exploit the heterosis between them, and then only inbred lines from different heterotic groups are crossed to give rise to the single-crosses. Inbred lines developed from these populations, either by selfing or by doubled-haploids, are subjected to high-intensity selection only for high heritability traits because the correlation of inbreds and their hybrids are too low for low heritability traits as grain yield. The inbred lines from one heterotic group are crossed to one or more elite inbreds from the opposite heterotic group and the testcrosses are evaluated in replicated trials in several environments for low heritability traits. One or more testcrosses (single-crosses) could outperform the current cultivars, and they could be released as single-crosses, with an existing elite inbred as one of the parents. At the end of the process the selected inbreds from any heterotic group are crossed to the selected inbreds from the opposite heterotic groups to develop several single-crosses that will be assessed in several environments for several years. If one or more new single-crosses outperform the existing cultivars they will be released as cultivars (Hallauer et al. 1988, Bernardo 2002)

\section{Varieties}

Improved varieties which include open-pollinated populations or the cross between them $\left(\mathrm{F}_{1}, \mathrm{~s}\right)$ should be used only when the use of hybrids is not possible. In general the use of hybrids is precluded in some species because of the high inbreeding depression of the lines or in less-developed regions. The improved varieties or $\mathrm{F}_{1}$ 's are developed by a procedure termed Recurrent Selection, which is a cyclical breeding procedure aimed to improve populations per se (intrapopulation) or the population crosses (interpopulation) performances while maintaining their genetic variability. In this procedure the frequencies of the favorable alleles of the traits under selection increase progressively leading to the improvement of the populations or of their crosses for several traits simultaneously. This is a dual-purpose procedure: i) to improve populations or their crosses to be released as open-pollinated or $F_{1}$ 's cultivars, respectively; and ii) to improve base populations to be used as sources of inbred lines to develop hybrids. The released hybrids are the best genotypes from the base populations or interpopulations, and then new cultivars could be developed from resampling these populations in the succeeding cycles of selection.

The recurrent selection consisted of four phases: 1) development of progenies for evaluation and for recombination; 2) evaluation of progenies in replicated trials in several locations; 3) selection of the superior progenies; 4) recombination of the selected progenies or progenies related to them. Recurrent selection is classified as: i) Intrapopulation Recurrent Selection in which the goal is to improve the performances of the populations per se; and ii) Interpopulation Recurrent Selection where the goal is to improve the performances of the crosses of two populations (interpopulation hybrids). Intrapopulation recurrent selection is to be used for those species where heterosis is not exploited in crosses, and interpopulation recurrent selection is to be used for the species where heterosis for the main traits present high magnitude and then it should be exploited in crosses. In intrapopulation programs, half-sib or full-sib are used as selection and recombination units, and in interpopulation programs halfsib and full-sib progenies are used as selection units and $S_{1}$ progenies for recombination units. Selfed progenies either $S_{1}$ or $S_{2}$ as units of selection should be avoided since their responses to selection have showed inferior results than those with non-selfed progenies (Souza Jr. 2001).

The impact of the recurrent selection in the development of cultivars could be evaluated by comparing the responses to selection of cultivars developed from the non-improved population and from after $n$ cycles of recurrent selection with the expression: $\Delta \mu=n R s+\left(i / \sigma_{P h}\right)\left(\sigma_{G n}^{2}-\sigma_{G 0}^{2}\right)$, where $\Delta \mu$ is the difference between the performance of the cultivars released from the different cycles of recurrent selection; $n, R s, i, \sigma_{P h}, \sigma_{G n}^{2}$, and $\sigma_{G 0}^{2}$, stand for the number of selection cycles, the average response to recurrent selection, the standardized selection differential, the square root of the phenotypic variance of the selection unit of 
the cultivars, and the genetic variance in the $n^{\text {th }}$ cycle and in the original cycle, respectively (Souza Jr. 2001). Thus, if the genetic variances of the original and after $n$ cycles of recurrent selection did not differ, the improvement of cultivars will be directly proportional to the response to recurrent selection, but if the genetic variance decreases during the cycles due to selection and/or due to the genetic drift effects, the improvement of the cultivars will no long be a linear function of the above expression; in fact they will be improved at a lower rate than the populations. This expression also shows that the maintenance of the genetic variability of the populations undergoing recurrent selection is of paramount importance to use the populations for a longterm as source of cultivars.

Several results in maize have shown that the genetic variability of the populations have been maintained at adequate levels even in high-intensity selection programs (Hallauer et al. 1988, Rezende and Souza Jr. 2000, Santos et al. 2005), the populations or the interpopulations have been improved for several traits at adequate levels (Hallauer et al. 1988, Rezende and Souza Jr. 2000, Santos et al. 2005, Santos et al. 2007), and the populations under recurrent selection have been sources of outstanding hybrids that could be released as cultivars (Betrán and Hallauer 1996, Hallauer et al. 1988, Souza Jr. et al. 2010). The sustainability of the plant breeding programs is the development of improved base populations and thus the recurrent selection programs might be considered as an essential part of the cultivar development programs.

\section{New tools for plant breeding}

Nowadays new tools from statistics and genomics could enhance the efficiency of the plant breeding programs in several ways. Some of these new tools have rise debate/doubts among the plant breeders, but some of them have become routine in several plant breeding programs, depending on the crop species and the level of development of the plant breeding programs.

One important tool is the transgenesis that allow the transference of genes among species, which led to the development of the transgenic crops. Thus, tolerant/resistant genotypes to several pathogens, insects, and herbicides have been developed, and nowadays transgenic cultivars from several species are being cultivated in several countries. Although this technique has been limited to simple inherited traits, it gave and likely will continue to give a great contribution to increase the productivity of the crops, nor in a direct way but indirectly reducing the losses caused by pathogens, pests, and weeds.
Other technique that will impact the plant breeding programs is the use of molecular markers. For instance, the introgression of favorable alleles of oligogenic traits via backcrossing is regularly carried out by the assistance of the molecular makers for both background and foreground selection, which reduces considerably the time needed for the introgression of favorable alleles into elite genotypes (Benchimol et al. 2005). Also, the use of molecular markers to estimate the genetic divergence of inbred lines to locate them in heterotic groups is as efficient as the use of diallel analysis, and then their use for this purpose has become a routine in maize breeding programs (Pinto et al. 2003) The use of QTL mapping have been limited use in plant breeding programs, mainly because for quantitative traits the statistical methods used to map QTL present several problems and most of the QTL for complex traits present high genotype by environment interaction. Thus, there are few results reporting success in the use of the mapped QTL in plant breeding programs (Bernardo 2008).

Recently, a new method termed Genome-Wide Selection has been proposed in which the genotypic values of the markers are computed using mixed models (Bernardo and Yu 2007), and then the genotypic values of the genotypes could be computed. Simulation and validation results have shown that this method has great potential to enhance the efficiency of plant breeding programs (Lorenzana and Bernardo 2009).

Statistical methods widely used in animal breeding to accommodate their largely unbalanced experiments, named Mixed Models, have been recognized as an important tools in plant breeding, but only recently they have been accepted by plant breeders. These models allow: i) the estimation of genotypic values (BLUEs or BLUPS) in unbalanced experiments; ii) the comparison of the genotypic values of the genotypes evaluated in different environments; iii) the prediction, to some extent, of genotypes not assessed in the experiments (Bernardo 2002, Fritsche Neto et al. 2010), (iv) the prediction of the genotypic values of plants from their molecular markers genotypes (Bernardo and Yu 2007).

Thus, there are some techniques from the biotechnology and from statistics that likely will have a great impact on the technologies used to develop cultivars. These new tools will increase our understanding on the inheritance of the traits, and the efficiency of the plant breeding programs will increase, mainly speeding-up the time to release new cultivars. However, it should be 
emphasized that they are tools to increase the efficiency not to replace the technologies used today to develop cultivars.

\section{The maize breeding project at the Department of Genetics/ESALQ/USP}

The Department of Genetics at the Agriculture College "Luiz de Queiroz" from the University of São Paulo has been using maize (Zea mays L.) as a model for allogamous crop species for training plant breeders in its graduate program. This choice was based on its importance as a crop, the high level of genetics and breeding studies, its annual cycle and high amount of seeds produced from self- or cross-fertilization, the technologies used to develop inbred lines is also used in autogamous crop species, the development of hybrids is also used in several autogamous species as sorghum, and the recurrent selection methods is also used in both autogamous as common beans and asexually propagated crops as eucalyptus. This strategy proved correct since the former students that graduated in the maize breeding laboratory nowadays are in several public and private institutions developing research with allogamous, autogamous, asexually propagated crops, and also perennial species. Just to mention a few crop species, they are developing cultivars of maize, melon, soybean, eucalyptus, common bean, banana, etc.

Some researches developed and under development at the Department of Genetics follow: 1) Recurrent Selection and Hybrid Breeding Programs: Three reciprocal recurrent selection projects are being conducted with different populations and different approaches. In one of these projects the interpopulation progenies are produced from $\mathrm{S}_{3}$ lines and a high-intensity of selection has been applied; the response to selection was higher than in conventional procedure (Rezende and Souza Jr. 2000), and the $S_{3}$ lines selected from their crosses were selfed to develop inbred lines, and most of their crosses (single-crosses) outperformed the current single-cross cultivars (Souza Jr. et al. 2010). Other approach was to conduct a procedure in which a cycle could be conducted in just one year. The results from three cycles showed that the response to selection on a per cycle basis was similar to those reported from the conventional procedure (Souza Jr and Pinto 2000, Santos et al. 2007). The third one was a conventional procedure that was conducted for three cycles, and the response to selection was similar to those reported in temperate germplasm (Santos et al. 2005). The overall results from these projects showed that it is possible to integrate the recurrent selection programs into an applied program aimed to develop hybrids as cultivars, mainly the procedure in which the $S_{3}$ lines were used to develop the interpopulation progenies since it allows the selection of lines for three generations, and the evaluation of the interpopulation progenies is an early evaluation of their combining ability. Also, reducing the time to conduct a cycle of recurrent selection could be an interesting procedure to integrate the recurrent selection with the development of cultivars. 2) Molecular Markers: i) QTL Mapping: Two $\mathrm{F}_{2}$ populations were developed and genotyped with microsatellite markers to study the inheritance of several traits by mapping QTL that control them. The $\mathrm{F}_{2: 3}$ progenies was used to phenotype both populations and for one of them the Design III was also used. Several traits as grain yield, components of grain yield as prolificacy, kernel-row number, number of kernels per row, grain weight, kernel oil content, stay-green, days to anthesis, days to silk extrusion, anthesis-silking interval, and reaction to Phaeosphaeria leaf spot, were recorded in several environments (location and years). Also the $\mathrm{F}_{2: 3}$ progenies from one of the populations were testcrossed to two testers genetically divergent for their tolerance to acid soils, and these testcrosses were evaluated in three environments differing in soil acidity level. The overall results of this project showed that the magnitudes of the genetic variances accounted for the mapped QTL for all traits were low, rarely exceeding $50 \%$ of the genetic variance, although the precision of the experiments were very high. These results, which are similar to those reported in the literature, showed that the statistical methods to map QTL, despite of its mathematical sophistication, are not capable to map adequately the genes that control quantitative traits, even in highly saturated maps. In any way they shed some light mainly in showing that the additive and dominance effects of QTL underlying these traits differ greatly in magnitude, and in their location in the genome since for some traits the QTL were not evenly distributed in the genome, but clustered in some genomic regions. An important feature is that all traits presented several QTL that interacted with environments, but for grain yield the vast majority of the QTL mapped presented a high interaction with environments (Lima et al. 2006, Moreira et al. 2009). ii) Marker-Assisted Selection: With the advent of the Genome-Wide Selection (GWS) (Bernardo and Yu 2007) a project was conducted to evaluate its efficacy. For grain yield, the most complex trait, the responses to phenotypic selection $(\mathrm{PhS})$ and GWS 
were $0.48 \mathrm{tha}^{-1}(5.5 \%)$ and $0.27 \mathrm{tha}^{-1}(3.1 \%)$ on a per cycle basis, respectively, and the ratio $\mathrm{GWS} / \mathrm{PhS}=0.56$ was similar to that reported by Lorenzana and Bernardo (2009). GWS is conducted after phenotypic selection, and considering that only one cycle will be conducted after the $\mathrm{PhS}$ selection, the sum of the responses to selection will be $0.75 \mathrm{tha}^{-1}(8.6 \%)$, enhancing considerably the response to selection on a per year basis. These results then showed that GWS is a procedure that could enhance the efficiency of the maize breeding programs, since it will be based only on the marker values of the young plants or of the seeds, speeding-up the programs. iii) Other successful molecular markers uses were in the allocation of the inbred lines to correct heterotic groups and in the marker-assisted backcrossing selection. Genetic divergence estimates from molecular markers and from specific combining ability allocated inbred lines to different heterotic groups similarly (Pinto et al. 2003); and the marker-assisted backcross selection allowed only three generations for the introgression of alleles from an inbred into another and to recover the genome of the recurrent parent (Benchimol et al. 2005). 3) Mixed models to predict untested hybrids: Two-hundred and fifty single-crosses were evaluated in thirteen environments (locations and years). Then, using mixed models, several percentages of hybrids were withdrawn from the data, and their performances were predicted. The results showed that above $20 \%$ of the hybrids withdrawn from the data the correlation between the predicted and assessed hybrids reduces significantly. Thus, the method was found to be efficient up to this limit (Fritsche Neto et al. 2010). 4) Detection of epistasis: The triple test-cross (TTC) design (Kearsey and Jinks 1968) was used to estimate the presence of epistasis for several traits. The original TTC and a modified TTC (Eta-Ndu and Openshaw 1999) in which the backcrossed progenies are crossed to testers were carried out. The overall results showed that for all traits recorded (grain yield and their components, flowering, plant stature, stay-green, and plant lodging) the epistasis were detected, but their effects were not unidirectional, they were not related to the best performing testcrosses, and for the non-correlated traits different genotypes presented significant epistatic effects. Epistatic effects were present in all traits assessed and therefore the additive-dominance model is incomplete to describe the variation of quantitative traits. Therefore, the additive and dominance genetic variances, heritability coefficients, as well as the responses to selection are biased to some extent 5) Theoretical $r$ esearches: Some examples of the theoretical researches follow: i) Response to Selection Under Small Effective Population Size (Souza Jr. et al. 2000); whose expression is: $R s=\left[i c\left(t \sigma_{A}^{2}+F_{t} D_{I}\right) /\right.$ $\left.\sigma_{P h}\right]-F_{t} I D$, and $i, c, t, F_{t}, \sigma_{A}^{2}, D_{l}$, , and $I D$ stand for the intensity of selection, the coefficient that depends on the recurrent selection method, the $t^{\text {th }}$ generation of selection, the inbreeding coefficient at the $t^{\text {th }}$ generation, the additive variance, the covariance of homozygous and dominance effects of the homozygotes, the square root of the phenotypic variance, and the inbreeding depression, respectively. With this expression it could be noted that if the effective population size is not managed the response to selection will be reduced. ii) Interpopulation Genetic Variances and Hybrid Breeding Programs (Souza Jr. 1992). In this research comparisons among all possible types of hybrids were carried out as those between single-crosses and modified single-crosses, single-crosses of partially inbred lines, etc. iv) Predicting the Range of Inbreeding Depression: the variance of inbreeding depression was developed (Souza Jr. and Fernandes 1997) as $\left.\sigma_{G I D}^{2}=\left[F_{g}-F_{t}\right)^{2} /\left(1-F_{t}\right)\right]\left[\sigma^{2} D\right.$ $\left.+(1 / 2) D_{2}+F_{t} H\right]$ for any two generations $\left(F_{t}\right.$ and $\left.F_{g}\right)$ of inbreeding, and reduces to $\sigma_{G I D}^{2}=\sigma^{2}{ }_{D}+(1 / 2) D_{2}$ for the non-inbred reference population $\left(F_{t}=0\right)$ and highly inbred lines $\left(F_{t}=1\right)$; here $\sigma_{D}^{2}, D_{2}$ and $H$ stand for the dominance variance, the variance of the dominance effects of the homozygotes, and the squared of the inbreeding depression; also a mating design was proposed to estimate the genetic variance of the inbreeding depression. A numerical evaluation showed that for grain yield in maize this variance is larger than less complex traits as plant height. v) Comparisons of Intra-, Interpopulation, and Modified Recurrent Selection Methods (Souza Jr. 1993). A comparison in the responses to selection in the populations per se and in the heterosis was developed, and the results showed that both intra- and interpopulation selection will not improve simultaneously the two populations and the heterosis, and a modification procedure was designed to fulfill the drawbacks of these selection methods. 
CL Souza Jr.

\section{Desenvolvimento de cultivares de espécies alógamas}

RESUMO - Os objetivos desta revisão foram apresentar o estado da arte das tecnologias utilizadas para desenvolver cultivares em espécies alógamas, excluindo as espécies perenes e as propagadas assexuadamente. Foi revista a estrutura genética destas espécies e suas relações com o desenvolvimento de cultivares, as tecnologias utilizadas para desenvolver híbridos e variedades de polinização aberta melhoradas e seus $F_{1}$ 's, e o impacto da biotecnologia e dos modelos mistos no desenvolvimento de cultivares. Um sumário dos resultados das pesquisas desenvolvidas no projeto de melhoramento de milho do Departamento de Genética da Escola Superior de Agricultura "Luiz de Queiróz" será apresentado.

Palavras-chave: cultivar, híbridos, marcadores moleculares, seleção recorrente, modelos mistos.

\section{REFERENCES}

Benchimol LL, Souza Jr. CL and Souza AP (2005) Microsatelliteassisted backcross selection in maize. Genetics and Molecular Biology 28: 789-797.

Bernardo R (2002) Breeding for quantitative traits in plants. Stemma Press, Woodbury, 369p.

Bernardo R (2008) Molecular markers and selection for complex traits in plants: learning from the last 20 years. Crop Science 48: $1649-1664$.

Bernardo R and Yu J (2007) Prospects for genome-wide selection for quantitative traits in maize. Crop Science 47: 1082-1090.

Betrán FJ and Hallauer AR (1996) Hybrid improvement after reciprocal recurrent selection in BSSS and BSCB1 maize populations. Maydica 41: 24-33.

Fritsche Neto R, Gonçalves MC, Vencovsky R and Souza Jr. CL (2010) Prediction of genotypic values of maize hybrids in unbalanced experiments. Crop Breeding and Applied Biotechnology 10: 32-39.

Eta-Ndu JT and Openshaw SJ (1999) Epistasis for grain yield in two $F_{2}$ populations of maize. Crop Science 39: 346-352.

Hallauer AR, Russell WA and Lamkey KR (1988) Corn breeding. In Sprague GF and Dudley JW (eds.) Corn and corn improvement. American Society of Agronomy, Madison, p. $463-564$.

Kearsey MJ and Jinks JL (1968) A general method of detecting additive, dominance and epistatic variation for metrical traits. I. Theory. Heredity 23: 403- 409.

Lima MLA, Souza Jr. CL, Bento DAV, Souza AP and Carlini-Garcia LA (2006) QTL mapping for grain yield and plant traits in a tropical maize population. Molecular Breeding 17: 227-239.

Lorenzana RE and Bernardo R (2009) Accuracy of genotypic value predictions for marker-based selection in biparental plant populations. Theoretical and Applied Genetics 120: 151161.
Moreira JUV, Bento DAV, Souza AP and Souza Jr. CL (2009) QTL mapping for reaction to phaeosphaeria leaf spot in a tropical maize population. Theoretical and Applied Genetics 119: $1361-1369$.

Pinto RMC, Souza Jr. CL, Carlini-Garcia LA, Garcia AAF and Souza AP (2003) Comparison between molecular markers and diallel crosses in the assignment of maize lines to heterotic groups. Maydica 48: 63-73.

Rezende GSP and Souza Jr. CL (2000) A reciprocal recurrent selection procedure outlined to integrate hybrid breeding programs in maize. Journal of Genetics \& Breeding 54: 57-66.

Santos MF, Moro GV, Aguiar AM and Souza Jr. CL (2005) Responses to reciprocal recurrent selection and changes in genetic variability in IG-1 and IG-2 maize populations. Genetics and Molecular Biology 28: 781-788.

Santos MF, Câmara TMM, Moro GV, Costa EFN and Souza Jr. CL (2007) Responses to selection and changes in combining ability after three cycles of a modified reciprocal recurrent selection in maize. Euphytica 157: 185-194.

Souza Jr. CL (1992) Interpopulation genetic variances and hybrid breeding programs. Brazilian Journal of Genetics 15: 643656.

Souza Jr. CL (1993) Comparisons of intra-, interpopulation, and modified recurrent selection methods. Brazilian Journal of Genetics 16: 91-105.

Souza Jr. CL (2001) Melhoramento de espécies alógamas. In Nass LL, Valois ACC, Melo IS and Valadares-Inglis MC (eds.) Recursos genéticos e melhoramento: plantas. Fundação MT, Rondonópolis, p. 159-199.

Souza Jr. CL and Fernandes JSC (1997) Predicting the range of inbreeding depression of inbred lines in cross-pollinated populations. Brazilian Journal of Genetics 20: 35-39.

Crop Breeding and Applied Biotechnology S1: 8-15, 2011 
Cultivar development of allogamous crops

Souza Jr. CL and Pinto RMC (2000) Responses to a short-term reciprocal recurrent selection procedure in maize. Maydica 45: 21-28.

Souza Jr. CL, Geraldi IO and Vencovsky R (2000) Response to recurrent selection under small effective population size. Genetics and Molecular Biology 23: 841-846.
Souza Jr. CL, Barrios SCL and Moro GV (2010) Performance of maize single-crosses developed from populations improved by a modified reciprocal recurrent selection. Scientia Agricola 67: $198-205$ 